\title{
Novel Technology for Phenol Wastewater Treatment Using Electrochemical Reactor
}

\author{
Yuncheng Xie, ${ }^{1}$ Ning Jiang, ${ }^{2}$ Wei Guan, ${ }^{1}$ Fangying Ji, ${ }^{2}$ Zhigang Xie, ${ }^{1}$ and Jing Zhang ${ }^{3}$ \\ ${ }^{1}$ Chongqing Key Laboratory of Environmental Materials \& Remediation Technologies, Chongqing University of Arts and Sciences, \\ Chongqing 402160, China \\ ${ }^{2}$ Key Laboratory of Three Gorges Reservoir Region's Eco-Environment, Chongqing University, Chongqing 400045, China \\ ${ }^{3}$ School of Environment Science and Spatial Informatics, China University of Mining and Technology, Jiangsu 221008, China
}

Correspondence should be addressed to Wei Guan; guanwei951030@126.com

Received 21 April 2015; Revised 21 July 2015; Accepted 30 July 2015

Academic Editor: Carlos A. Martínez-Huitle

Copyright (C) 2015 Yuncheng Xie et al. This is an open access article distributed under the Creative Commons Attribution License, which permits unrestricted use, distribution, and reproduction in any medium, provided the original work is properly cited.

\begin{abstract}
There are various electrochemical approaches to save energy, mostly by means of equipment improvement coupled with other water treatment technologies. Replacement of DC power with pulse power, modified reactor coupled with photocatalysis can decrease cost. But more or less additional input is developed, or infrastructure has to be replaced. In this paper, an N-Step electrochemical reactor, based on stage reaction modeling, is put forward. On the basis of not changing equipment investment and by adjustment of the operating current density at different levels, power consumption decreases. This model develops a foundation of electrochemical water treatment technology for the engineering application.
\end{abstract}

\section{Introduction}

As the origin of life, water is considered a foundation of survival of all life on earth. Since the 1950s, with the development of chemical industry, a large amount of industrial wastewater, especially hypersaline wastewater, was discharged into water bodies, not only to cause water biological birth defects and a large number deaths [1] but also to develop a serious threat to human survival. Therefore, the water pollution problem needs to be solved. Large amounts of hypersaline wastewater emission, doubtlessly, results in an embarrassing problem to the environmental protection. In view of its characteristics of "hypersaline," if the biochemical method is adopted, the high concentration inorganic salt elements such as $\mathrm{Na}^{+}, \mathrm{Cl}^{-}, \mathrm{K}^{+}$, $\mathrm{Ca}^{2+}$, and $\mathrm{SO}_{4}{ }^{2-}[2-4]$ in wastewater must restrict the growth of microorganism in the sludge and even kill microorganisms [5-7]. Therefore, using common biochemical method to treat hypersaline wastewater is not adaptable to meeting emissions standards.

Because of the characteristic of hypersalinity, it is wastewater's good electrical conductivity that provides good alternatives for electrochemistry to treat hypersaline wastewater $[8,9]$. Catalytic electrooxidation refers to the organic matter to gain or to lose electrons in the external electric field of the reactor through redox reaction or through the anode to produce the strong oxidizing agents such as ${ }^{\circ} \mathrm{OH}$ and $\mathrm{H}_{2} \mathrm{O}_{2}$ oxidizing organic compounds $[10,11]$. The organic matter degradation pathway is more perfect, without any additional pollutants, and this method is often called organic matter's catalytic electrooxidation. This process can be used as deep wastewater treatment separately. It can also be used as pretreatment process of biochemical method to improve the effluent $\mathrm{BOD}_{5} / \mathrm{COD}$, to provide better support for subsequent biological treatment $[12,13]$. The high operating cost of electrochemical processes is the major obstacle of their wide use. It is not the first choice for wastewater treatment process. Main causes of the high cost of electrochemical processes are the electrode material, the structure of reactor, and so forth.

With respect to engineering application, electrochemical reactor is developed which has the energy-saved characteristics and it is important for the reactor to be adaptable to hypersaline organic wastewater treatment [14-17]. 
Accordingly, on the basis of wastewater characteristics and electrochemical reactions' characteristics, N-Step electrochemical reactor operation, with multiple powers to make real-time operating current density under the limit levels, with current efficiency in each stage to reach about $100 \%$, is put forward. It can reduce the input power consumption and also can greatly reduce the reaction time, so that the reactor equipment investment is reduced.

\section{Experiments}

2.1. Experimental Apparatus. Experimental apparatus mainly is electrochemical reactor, DC power supply, plate, wire, peristaltic pump, rubber tube, bucket, and so forth. The apparatus is shown in Figure 1, and the specific process is shown in Figure 2.

The shape of electrode reactor is cubic organic glass with size of $10 \times 5 \times 15 \mathrm{~cm}$, and effective volume is $0.5 \mathrm{~L}$ with a hole at the bottom of the reactor reaction zone to ensure uniform water distribution. The decorated overflow wire locates at the top. Cathode and anode plate with size of $10 \times$ $10 \mathrm{~cm}$ survive on either reactor side. Cathode is composed of $\mathrm{Ti}$ plate, whereas anode consists of $\mathrm{RuO}_{2}-\mathrm{IrO}_{2} / \mathrm{Ti}, \mathrm{PbO}_{2} / \mathrm{Ti}$ plate. Cathode connected to a DC power's negative electrode; however, anode connected to the power's positive electrode. By means of the DC power supply voltage current size can be reflected. Activated carbon, with particle size of $35 \mathrm{~mm}$, filled in the space between the plates. Reactor can be introduced into the reaction zone through peristaltic pump, and water can be collected in both inlet and outlet by buckets.

\subsection{Experiment and Analysis Methods}

2.2.1. Experimental Water Samples. This experiment uses the mixed phenol wastewater. Its main organic matter is phenol with molecular formula of $\mathrm{C}_{6} \mathrm{H}_{6} \mathrm{O}$ and with relative mass of 94.11 .

\subsubsection{Experimental Methods}

Pretreatment of Activated Carbon and Plate. Plate was immersed into dilute $\mathrm{HCl}(0.1 \mathrm{~mol} / \mathrm{L})$ and then immersed in dilute $\mathrm{NaOH}(0.1 \mathrm{~mol} / \mathrm{L})$ to remove electrode surface grease and residual organic matter and then washed with deionized water. Activated carbon was first washed with deionized water and then is boiled for $30 \mathrm{~min}$ in dilute $\mathrm{HCl}(0.1 \mathrm{~mol} / \mathrm{L})$ twice, after it was boiled for $30 \mathrm{~min}$ in dilute $\mathrm{NaOH}(0.1 \mathrm{~mol} / \mathrm{L})$ twice. And then it is put in deionized water to boil for $30 \mathrm{~min}$ twice. Finally, it was transferred to electrochemical reactor. The prepared $\mathrm{Na}_{2} \mathrm{SO}_{4}$ solution (3\%) was pumped into the reactor with peristaltic pump for electrolysis for $30 \mathrm{~min}$. But activated carbon has adsorption performance, and, therefore, before formal experiment, activated carbon is socked into phenol wastewater until concentrations are almost the same before and after phenol soaking.

Phenol Wastewater Degradation Experiment. To prepare phenol wastewater, $0.1 \mathrm{~mol} / \mathrm{L}$ of anhydrous $\mathrm{Na}_{2} \mathrm{SO}_{4}$ as wastewater electrolyte is added, and through peristaltic pump

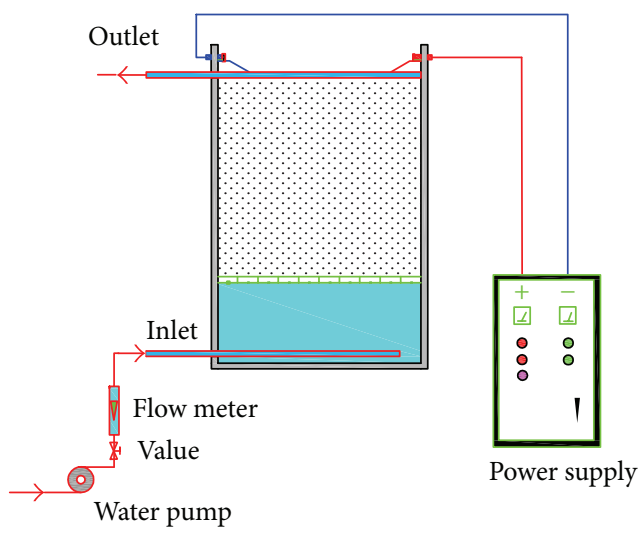

FIgURE 1: Experimental apparatus.

the wastewater is pumped into the three-dimensional electrode reactor. By adjusting the power, the preset electric current density is kept for the whole reaction. After the electrolytic reaction, water samples are taken out to go on the next treatment. Next treatment is the same as the previous one.

\subsubsection{Analysis Methods}

Phenol Determination. The determination of phenol adopted 4-amino antipyrine method [18].

COD Determination. Determination of COD adopted potassium dichromate reflux method [19].

Calculation of Mass Transfer Coefficient. The rate of electrochemical reaction depends on the speed of mass transfer. In the electrochemical reaction system, the mass transfer effect was greatly enhanced by the addition of the filler particles. However, organic compound needs to be disused for the surface of the anode to be oxidized.

In electrochemical system, mass transfer mainly includes convection, diffusion, and electric migration, and mass transfer coefficient calculation methods are hydraulic method, rotating disk electrode method, and empirical method. Hydraulic calculation of mass transfer coefficient does not involve the concentration of organic wastewater, the axial back mixing, electrochemical operating conditions, and other factors. Rotating disk electrode calculation of mass transfer coefficient does not consider the effect of reactant species. For the complex industrial wastewater, this method is not adaptable to the calculation of mass transfer coefficient $k_{m}$. Empirical method is our laboratory results, coupled with the hydraulics, electrochemical, and liquid properties and bed configuration factor, and the influence of backmixing is considered, and the consistence with experimental results is better than the former two methods.

Through a lot of experimental research, raw water organic matter concentration, operating electric current density, plate materials, and other factors are introduced, and the influence of the radial, axial backmixing is considered, and general nonlinear measurement equation of mass transfer coefficient 


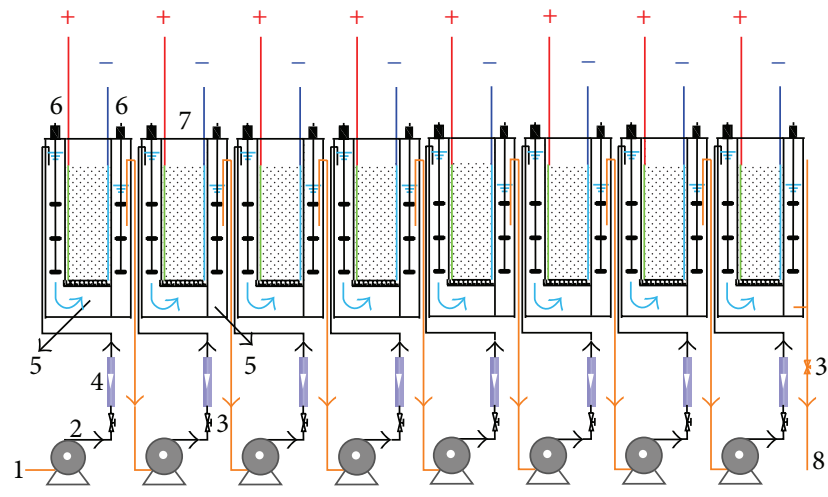

(a)

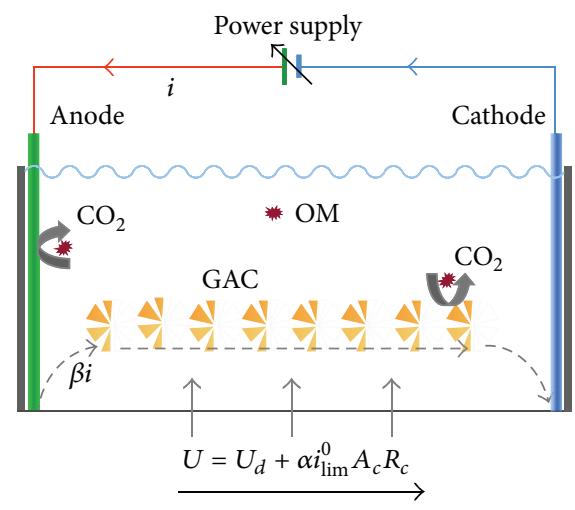

(b)

Figure 2: Treatment process of phenol wastewater. (a) Treatment process of phenol wastewater. (b) Oxidation mechanism of organics in a single reactor.

is put forward on the basis of reactor geometrical configuration, liquid phase characteristics, and operating current density [20]:

$$
\begin{aligned}
& k_{m} \\
& =\sqrt{\frac{i_{R} \mathrm{Sc}^{1 / 3} D}{n F c_{0} \varepsilon d_{p}\left(R_{H} / y_{0}\right)^{\chi}}\left(0.765 \mathrm{Re}^{0.18}+0.365 \mathrm{Re}^{0.614}\right)},
\end{aligned}
$$

where $i_{R}$ is operating current density; Sc is the Schmidt number; $D$ is diffusion coefficient; $d_{p}$ is packing diameter; $R_{H}$ is hydraulic radius; $y_{0}$ is plate length; $\chi$ is correction coefficient, this paper takes 0.3 ; and $\mathrm{Re}$ is the Reynolds number.

The coefficients of hydraulic computation formula are as follows:

$$
\begin{aligned}
\operatorname{Re} & =\frac{u d_{e}}{v}, \\
\mathrm{Sc} & =\frac{v}{D}, \\
D & =\frac{R T U^{\infty}}{|z| F}=\frac{R T \sigma_{m}{ }^{0}}{z^{2} F^{2}},
\end{aligned}
$$

where $v$ is dynamic viscosity of water; $R$ is gas constant, $8.314 \mathrm{~J} /(\mathrm{mol} \cdot \mathrm{K}) ; T$ is temperature, and $K: \sigma_{m}{ }^{0}$ is molar conductivity, $S \cdot \mathrm{m} / \mathrm{mol}$. As can be seen from formula (3)-(6), the methods of increasing mass transfer coefficient [21] are as follows.

Increase of Inlet Water Velocity of the Reactor. Increased velocity can increase Reynolds number to strengthen mass transfer. Reduction of the water area can complete the task. The shape of the reactor tends to be a tubular shape.

Reduction of the Raw Water Organic Matter Concentration. Organic matter concentration increases, and the viscosity of wastewater also increases, which affect the mass transfer. But when wastewater is emitted, water quality has been determined and thus alteration of organic matter concentration in wastewater to strengthen mass transfer cannot be achieved.

Improvement of Wastewater Conductivity. Increasing the salinity of water can increase the working voltage in the same electric field intensity; thus, the electromigration of these reaction particles is promoted. And at the same time increasing the response current and the local backmixing effects caused by concentration difference is weakened.

Reduction of Size of Packing Materials. The particle size is smaller, the packed bed void fraction is smaller, and the local velocity increases to increase the Re values. In addition, the fillers with small particle size can reduce the reactor hydraulic radius reaction, so as to reduce the influence of backmixing.

Double electric layers are important factors affecting mass transfer; the smaller the thickness, the larger the mass transfer speed.

Reaction in Large Operating Current Density. If the operating current density is larger, the oxidation of organic matter is faster, and the oxidation zone goes into deeper region. Local area organic matter concentration difference is less, so that the concentration polarization is effectively reduced.

\section{Results and Discussion}

Adoption of N-Step electrochemical reactor to treat phenol wastewater obtains ideal results. Compared with the constant current operation mode, N-Step electrochemical reactor decreases the cost and lays the foundation for engineering applications.

3.1. Comparison of Phenol Wastewater Treatment by N-Step Mode with Constant Current Electrochemical Reactor. As shown in Figure 3, for treatment of the same wastewater with constant current and N-Step operation mode, respectively, organic oxidation is the control step at the early stage of 


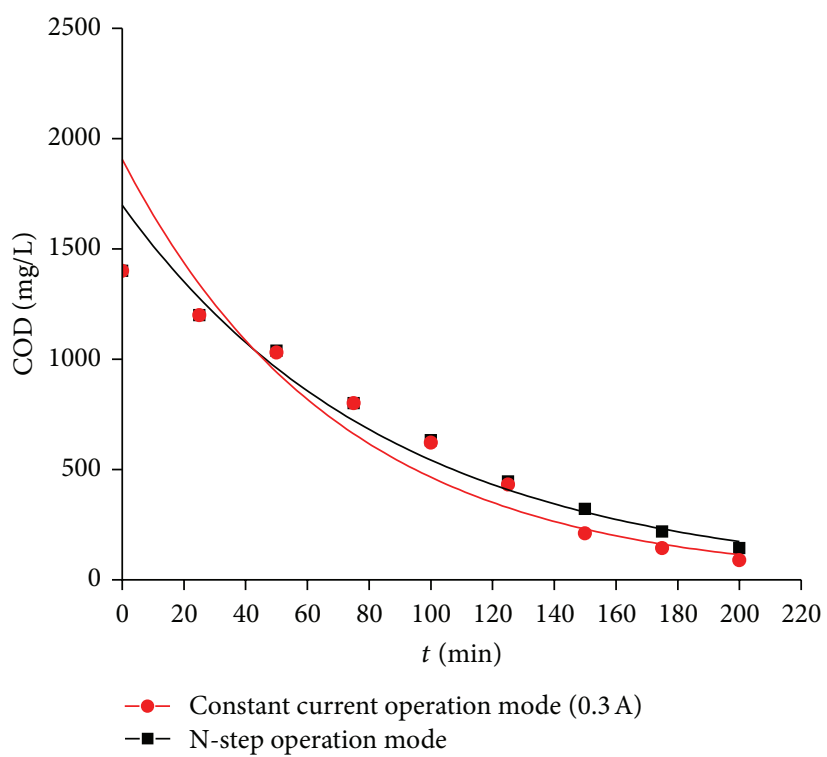

(a)

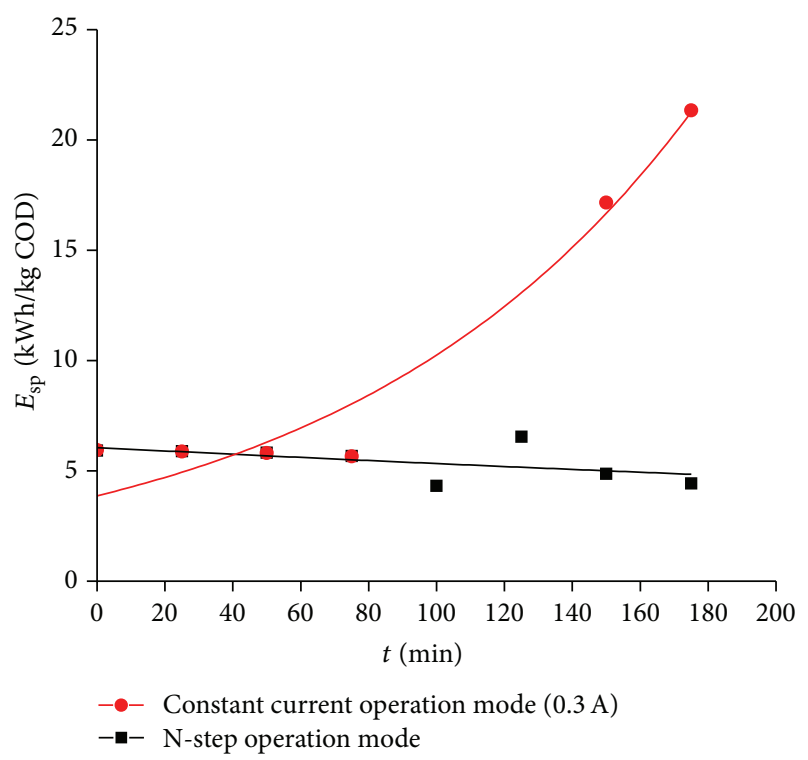

(b)

FIGURE 3: Variation of COD using different operating mode over time. (a) Variation of remaining COD concentration over time. (b) Power consumption using different operating mode over time.

organic matter oxidation due to $i_{\text {app }}<i_{\text {lim }}$. So, at the early stage of organic matter oxidation, the COD changes in constant current and N-Step operating mode are entirely consistent, as shown in Figure 3(a). Under the two operating modes, the difference of organic matter removal is not obvious. But, with cross flow operation mode, side effects increase, power consumption increases at the rear stage of organic matter oxidation due to $i_{\text {app }}>i_{\text {lim }}$, as shown in Figure 3(b), and adoption of cross flow operation mode treats phenol wastewater not to be economic. When N-Step electrochemical reactor is used to treat wastewater, power consumption shows the stepwise decreasing trend.

\subsection{Different Wastewater of Various Phenol Concentrations} to be Treated by N-Step Electrochemical Reactor. The various phenol concentrations of wastewater are prepared. Influence of initial concentration on the treatment effect is determined by analysis of the change of phenol and COD concentration after several periods of running the electrochemical reactor, where $\mathrm{RuO}_{2}-\mathrm{IrO}_{2} / \mathrm{Ti}$ is used as anode at constant salinity and constant flowing rate.

Wastewater with phenol concentrations of 400, 600, 800 , and $600 \mathrm{mg} / \mathrm{L}$ was prepared, respectively. N-Step electrochemical reactor treats the said wastewater at constant $3 \%$ electrolyte (anhydrous $\mathrm{Na}_{2} \mathrm{SO}_{4}$ ) concentrations and at constant $0.6 \mathrm{~L} / \mathrm{h}$ input water flow rate of peristaltic pump. In order to ensure each level of organic oxidation in reaction, the operating current density at various levels should be determined according to formula (3)-(7), to reach minimum overall operating cost. The change of phenol removal rate and COD concentration over time are shown in Figures 4 and 5, respectively.

As can be seen in Figure 4, at the same flow rate, the same anode, the same salinity, and the same reaction time, the phenol removal percentage in phenol wastewater with initial concentration $600 \mathrm{mg} / \mathrm{L}$ reached $83.144 \%$, the highest in the figure. But 4 kinds of wastewater are treated at various current operation modes; however, N-Step operating mode is used, so that the difference of operating current density is large and wastewater works by the removal rate cannot be identified. But it is concluded that the required current density is larger at large raw water phenol concentration compared with low concentration wastewater under the same operating series. Or, compared with low concentration wastewater, at each level adopting the same current density, if higher concentration wastewater is achieved in the same removal rate, more series is required. Therefore, when the raw water phenol concentration is higher, the power consumption of per-ton water processing will be higher.

As can be seen in Figure 5, the removal rate of phenol wastewater with initial concentration $600 \mathrm{mg} / \mathrm{L}$ is the maximum at the same flow velocity, the same anode, the same salinity, and the same reaction time. As for phenol removal, it cannot be determined for COD removal effect in $600 \mathrm{mg} / \mathrm{L}$ phenol wastewater to be optimal, but it can be identified indirectly by the size of the power consumption. From Figure 5(h) it can be seen that when the phenol initial concentration is $600 \mathrm{mg} / \mathrm{L}$, power consumption is the minimum. Too high or too low initial concentration will increase wastewater treatment cost. The main reason is that when the organic matter concentration in raw water becomes larger, the same removal percentage required more electricity to achieve the same result. When organic matter concentration in raw water is low, the required electricity is reduced, but the current density is too small, the removal percentage is very low. Therefore, only raw water concentration is moderate; removal of per-COD power consumption need the minimum power consumption. 


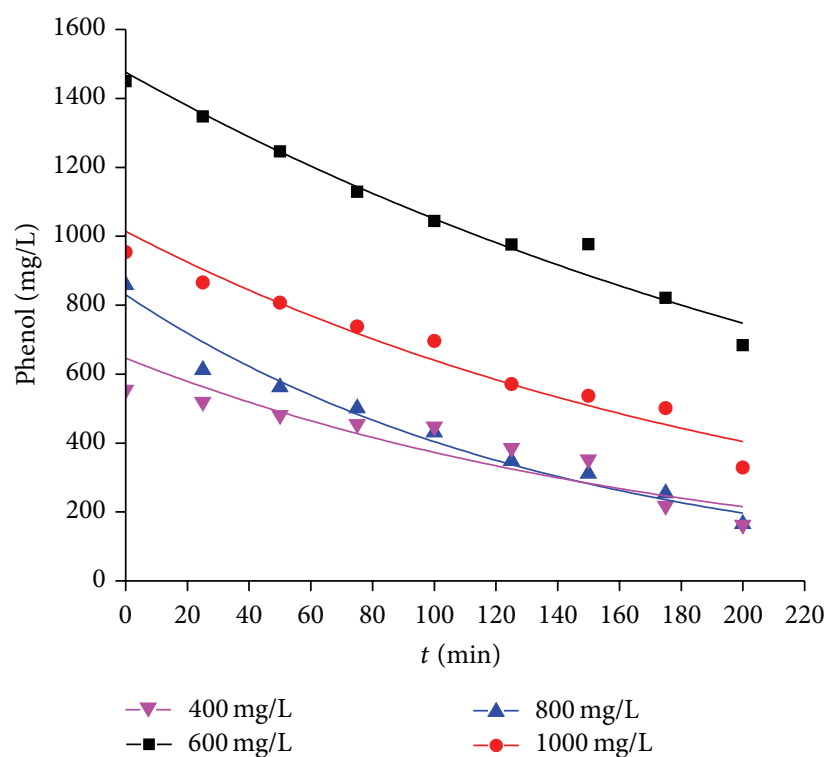

(a)

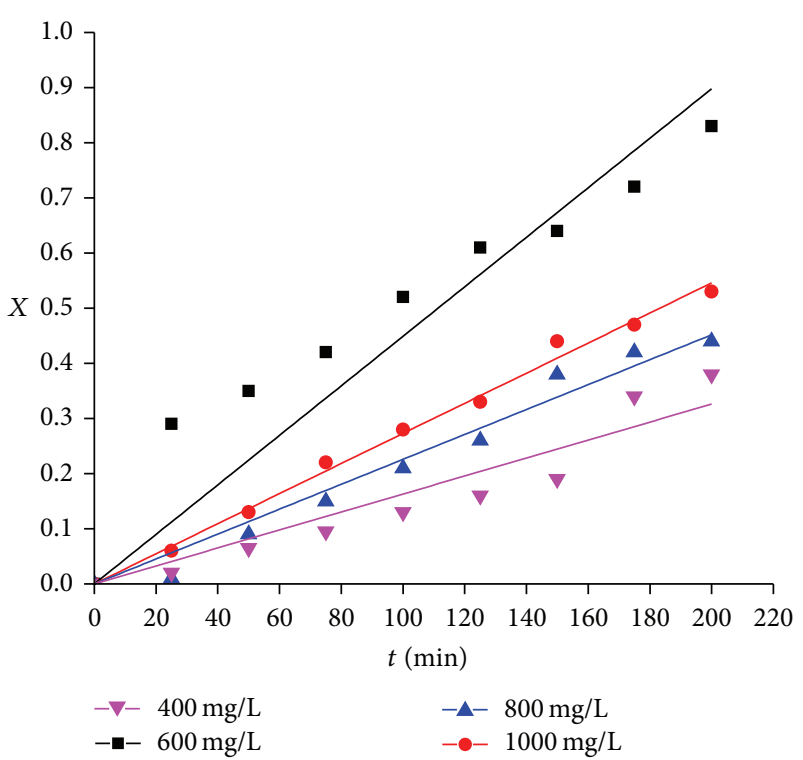

(b)

FIGURE 4: Variation of phenol concentration in different initial concentration of wastewater over time. (a) Variation of remaining phenol concentration over time. (b) Removal rate of phenol over time.

As can be seen in Figure 5, when N-Step electrochemical reactor treats different mass phenol concentration wastewater, per-COD power consumption tends to be gradually reduced and therefore is consistent with theoretical model; the more the series are, the less the energy need. Table 1 is the relation and related coefficient treating different concentration phenol wastewater. But the actual processing effect requires further inspection, because it is uncertain whether it is consistent with concentration prediction model.

It is needed to test similarity degree between theoretical value and measured values with rank tests. According to the theory and measured data (Table 2), use of $\mu_{1}$ and $\mu_{2}$ expresses the mean of theoretical and the measured data at significance level $\alpha=0.05$. Suppose that test is

$$
\begin{aligned}
& \mathrm{H}_{0}: \mu_{1}=\mu_{2} ; \\
& \mathrm{H}_{1}: \mu_{1} \neq \mu_{2} .
\end{aligned}
$$

Data is arranged from small to large, the sample rank of the COD for theoretical value of different phenol concentrations wastewater would be $r_{1}(400 \mathrm{mg} / \mathrm{L})=1+2+3+4+$ $5+6+11+15+17=64$, respectively, when $\mathrm{H}_{0}$ is true, $E\left(R_{1}\right)=1 / 2 n_{1}\left(n_{1}+n_{2}+1\right)=85.5, D\left(R_{1}\right)=1 / 12 n_{1} n_{2}\left(n_{1}+\right.$ $\left.n_{2}+1\right)=128.25$, and when $\mathrm{H}_{0}$ is true, approximately $R_{1} \sim N$ $(85.5,128.25)$, rejection region is as follows:

$$
\frac{\left|r_{1}-85.5\right|}{\sqrt{128.25}} \geq z_{0.025}=1.96
$$

Now observations $r_{1}=64$ substitute into the rejection region calculation value $1.90<1.96$, so $\mathrm{H}_{0}$ is accepted, and there was no significant difference between theoretical COD and actual COD.

Similarly, when the initial phenol concentration of wastewater is 600,800 , and $1000 \mathrm{mg} / \mathrm{L}$, respectively, $r_{1}$ values

\begin{tabular}{|c|c|c|}
\hline & COD & $E_{\mathrm{sp}}$ \\
\hline \multicolumn{3}{|l|}{$\mathrm{C}_{0}\left(\mathrm{C}_{6} \mathrm{H}_{6} \mathrm{O}\right) \mathrm{mg} / \mathrm{L}$} \\
\hline \multicolumn{3}{|l|}{400} \\
\hline \multicolumn{3}{|c|}{ Comparison expression } \\
\hline Theoretical value & $y=1128.2 e^{-0.015 x}$ & $y=12.752 e^{-0.002 x}$ \\
\hline Actual value & $y=993.17 e^{-0.004 x}$ & $y=46.214 e^{-0.01 x}$ \\
\hline \multicolumn{3}{|l|}{$R^{2}$} \\
\hline Theoretical value & 0.9914 & 0.9384 \\
\hline Actual value & 0.9831 & 0.9901 \\
\hline \multicolumn{3}{|l|}{600} \\
\hline \multicolumn{3}{|c|}{ Comparison expression } \\
\hline Theoretical value & $y=1720 e^{-0.013 x}$ & $y=13.87 e^{-0.002 x}$ \\
\hline Actual value & $y=1437.4 e^{-0.008 x}$ & $y=39.672 e^{-0.009 x}$ \\
\hline \multicolumn{3}{|c|}{ 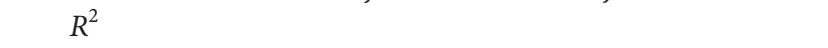 } \\
\hline Theoretical value & 0.94 & 0.9122 \\
\hline Actual value & 0.9438 & 0.9332 \\
\hline \multicolumn{3}{|l|}{800} \\
\hline \multicolumn{3}{|c|}{ Comparison expression } \\
\hline Theoretical value & $y=2220.5 e^{-0.011 x}$ & $y=14.756 e^{-0.001 x}$ \\
\hline Actual value & $y=1740.2 e^{-0.003 x}$ & $y=37.116 e^{-0.005 x}$ \\
\hline \multicolumn{3}{|c|}{ 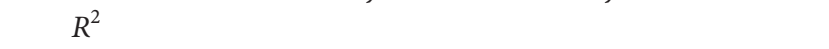 } \\
\hline Theoretical value & 0.9813 & 0.8958 \\
\hline Actual value & 0.9833 & 0.9748 \\
\hline \multicolumn{3}{|l|}{1000} \\
\hline \multicolumn{3}{|c|}{ Comparison expression } \\
\hline Theoretical value & $y=2859.4 e^{-0.011 x}$ & $y=14.572 e^{-0.0008 x}$ \\
\hline Actual value & $y=2323.3 e^{-0.005 x}$ & $y=27.663 e^{-0.003 x}$ \\
\hline \multicolumn{3}{|c|}{ ( } \\
\hline Theoretical value & 0.9657 & 0.7428 \\
\hline Actual value & 0.9924 & 0.9797 \\
\hline
\end{tabular}

TABLE 1: Relation and related coefficient to treat different concentration phenol wastewater. 


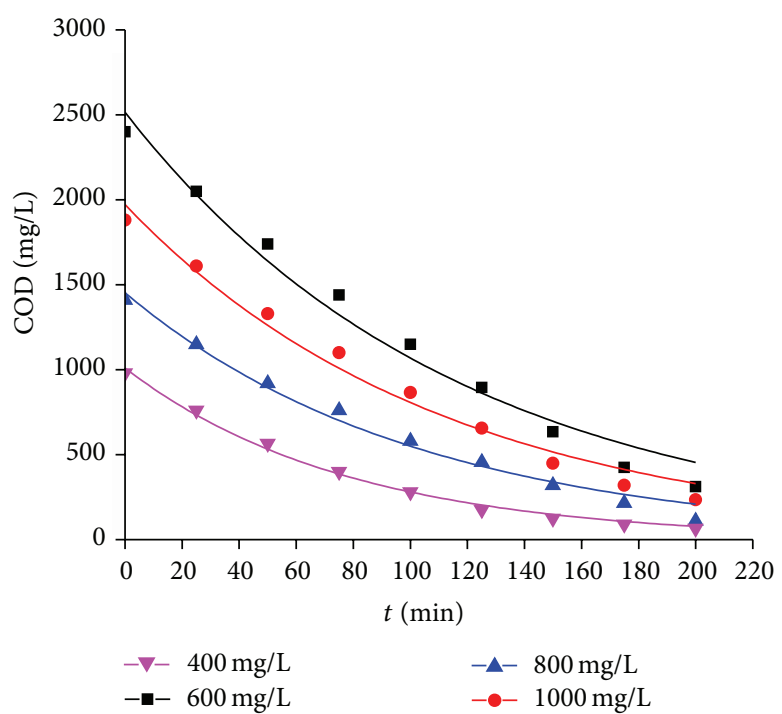

(a)

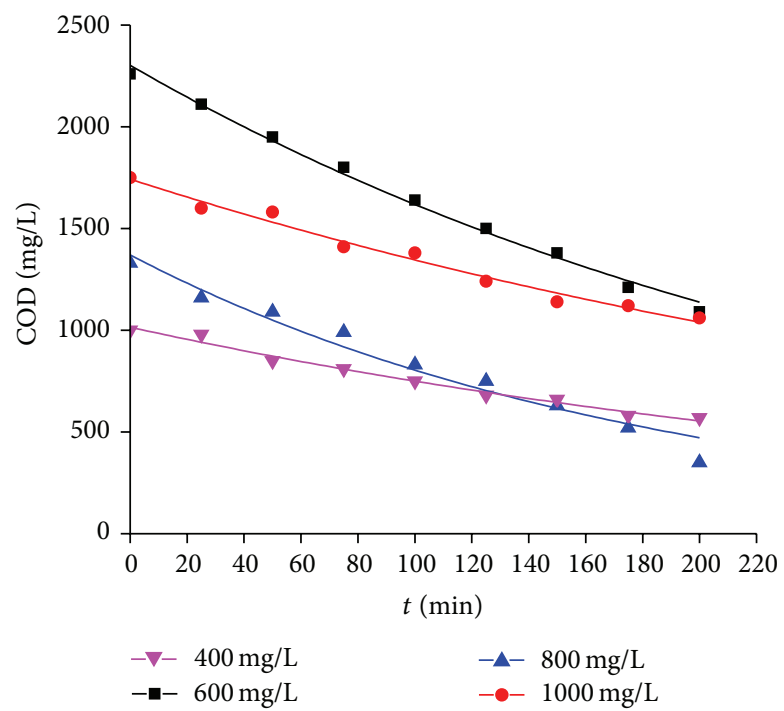

(c)

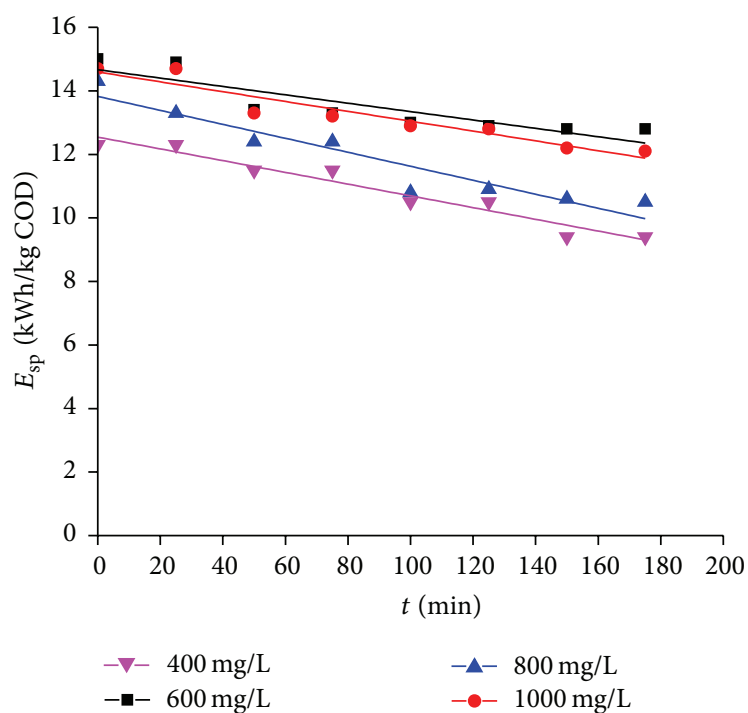

(e)

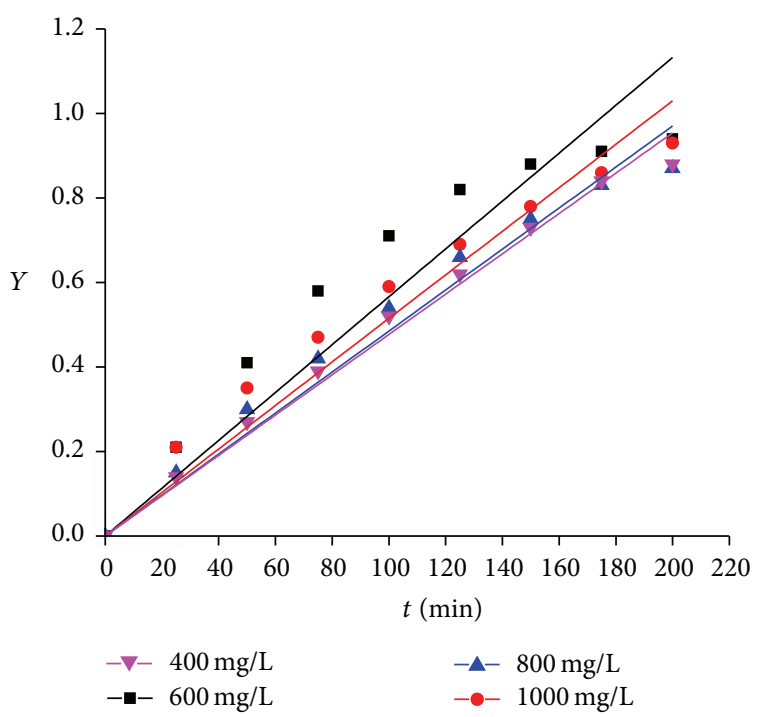

(b)

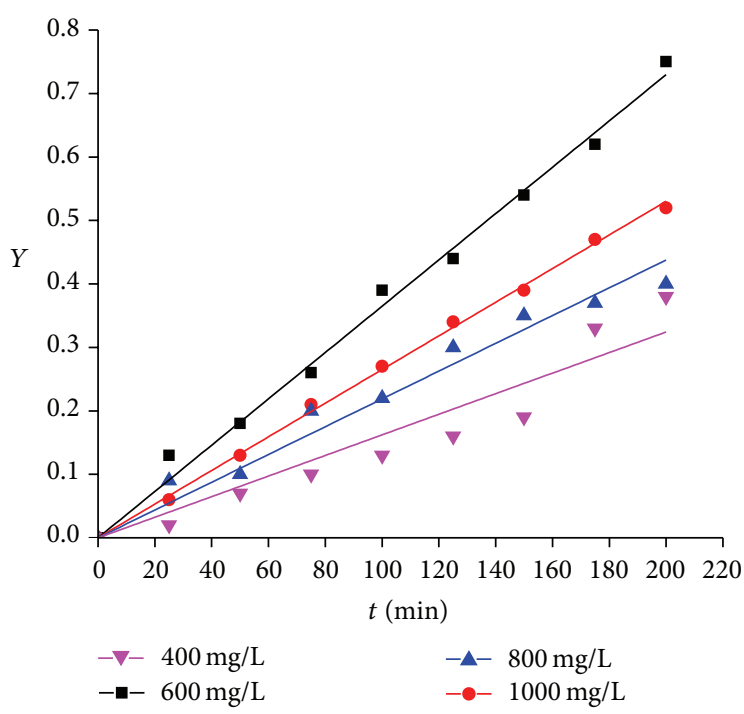

(d)

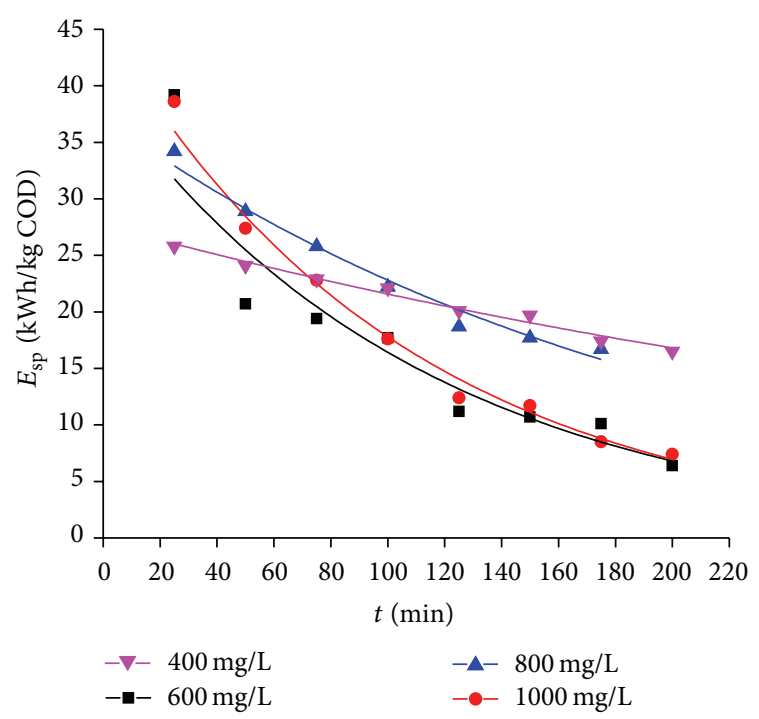

(f)

Figure 5: Continued. 


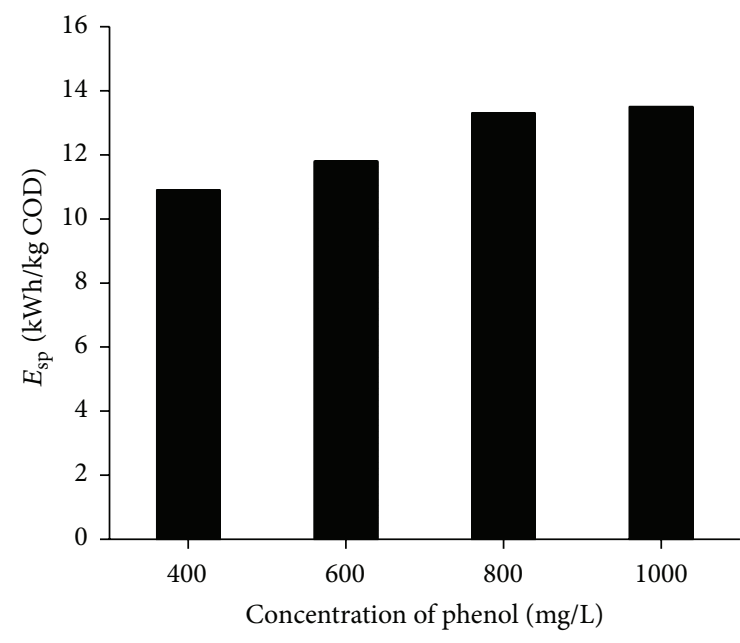

(g)

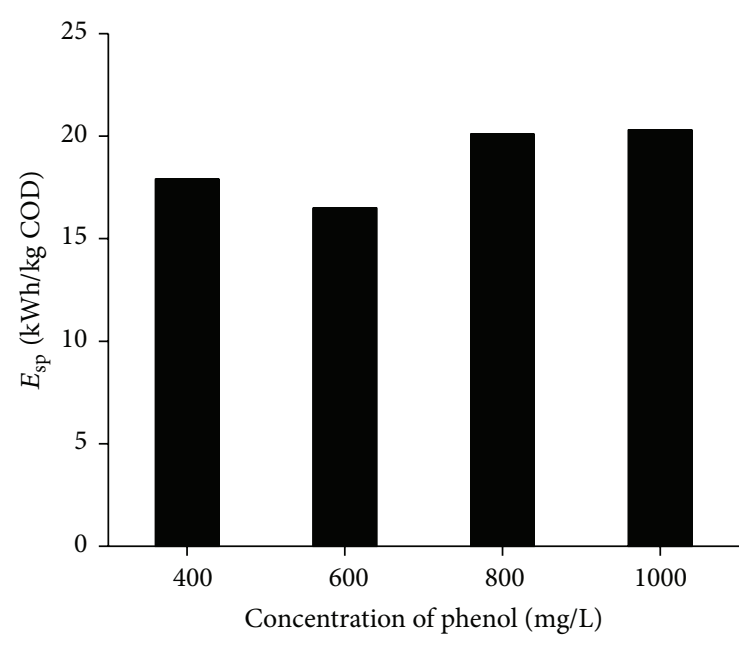

(h)

FIGURE 5: Variation of COD and power consumption in different initial concentration wastewater over time. (a) Variation of theoretical COD concentration over time. (b) Removal rate variation of theoretical COD in different initial concentration wastewater over time. (c) Measured COD in different initial concentration wastewater over time. (d) Removal rate variation of actual COD in different initial concentration wastewater over time. (e) Theoretical power consumption of different initial concentration wastewater treatment over time. (f) Actual power consumption of different initial concentration wastewater over time. (g) Average theoretical power consumption in different initial concentration of wastewater treatment. (h) Average actual power consumption in different initial concentration of wastewater treatment.

73, 68, and 70, respectively, substitute into the rejection region, its value was $1.1,1.54$, and 1.37 , respectively, all less than 1.96 , so $\mathrm{H}_{0}$ is accepted, and there was no significant difference between theoretical COD and actual COD.

A significant difference between theoretical and actual power consumption was verified with the same method as those between theoretical COD and actual COD. When the initial phenol concentration of wastewater is $400,600,800$, and $1000 \mathrm{mg} / \mathrm{L}, r_{1}$ value is $59,64,36$, and 40 , respectively. When $\mathrm{H}_{0}$ is true, $E\left(R_{1}\right)=1 / 2 n_{1}\left(n_{1}+n_{2}+1\right)=68, D\left(R_{1}\right)=$ $1 / 12 n_{1} n_{2}\left(n_{1}+n_{2}+1\right)=90.67$, and rejection region is

$$
\frac{\left|r_{1}-68\right|}{\sqrt{90.67}} \geq z_{0.025}=1.96 \text {. }
$$

Observation values are introduced into the rejection region, its value was $0.11,0.42,3.36$, and 2.94 , respectively; when the initial phenol concentration of wastewater is 400 , $600 \mathrm{mg} / \mathrm{L}$, respectively, there was no significant difference between theoretical and actual power consumption. The reason is that when wastewater organic concentration is high, the removal of organic matter is small at small operating current density to process wastewater. And, in the practical wastewater treatment, the fluctuation of water may cause wastewater power consumption to rise sharply at specific level, though small removal percentage survives in certain levels. This phenomenon causes the order of the actual power consumption to distribute at a wide range, to influence the outcome of the rank tests.

\subsection{Different Electrolyte Concentration Phenol Wastewater} Treatment Using N-Step Electrochemical Reactor. The various phenol concentrations of wastewater are prepared. Influence of initial concentration on the treatment effect is determined by analysis of the change of phenol and COD concentration after several periods of running the electrochemical reactor, where $\mathrm{PbO}_{2} / \mathrm{Ti}$ is used as anode at constant salinity and constant flowing rate.

Salinity concentration of $1 \%, 2 \%, 3 \%$, and $4 \%(\mathrm{~g} / \mathrm{mL})$ wastewater were prepared, phenol initial concentration is $600 \mathrm{mg} / \mathrm{L}$, and peristaltic pump inlet rate is $0.6 \mathrm{~L} / \mathrm{h}$. Due to the same organic matter concentration of the four kinds of wastewater, the same value of operating current density for the four kinds of wastewater at all levels is adopted, and the change over time of phenol and COD concentration removal percentage is shown in Figures 6 and 7.

As can be seen in Figure 6, in the same organic matter concentration, the same flow rate, the same anode, and the same reaction time, removal percentage of phenol wastewater with salinity being $1 \%, 2 \%, 3 \%$, and $4 \%$ reached $79.9 \%$, $93.359 \%, 85.1 \%, 9$ and $1.781 \%$, respectively. While 4 kinds of wastewater are not in constant current operation mode treatment, the organic matter concentration of wastewater is the same, so at each level current density of N-Step electrochemical reactor operating mode is the same. As can be seen in Figure 6, when raw water salinity is $2 \%$, the phenol removal efficiency is the best. Increasing wastewater salinity can increase wastewater conductivity and promote electron transfer. When the salinity is high, $\mathrm{SO}_{4}{ }^{2-}$ will be adsorbed on the surface of $\mathrm{Ti} / \mathrm{PbO}_{2}$ anode, which affects the production of ${ }^{\bullet} \mathrm{OH}$ and then influences the electrochemical reaction. In addition, from the economy, the more the wastewater electrolyte is, the more the processing cost is.

As can be seen in Figure 7, it is consistent with phenol removal. When the salinity is $2 \%$, COD removal efficiency is the best. The main reason is consistent with phenol removal. 


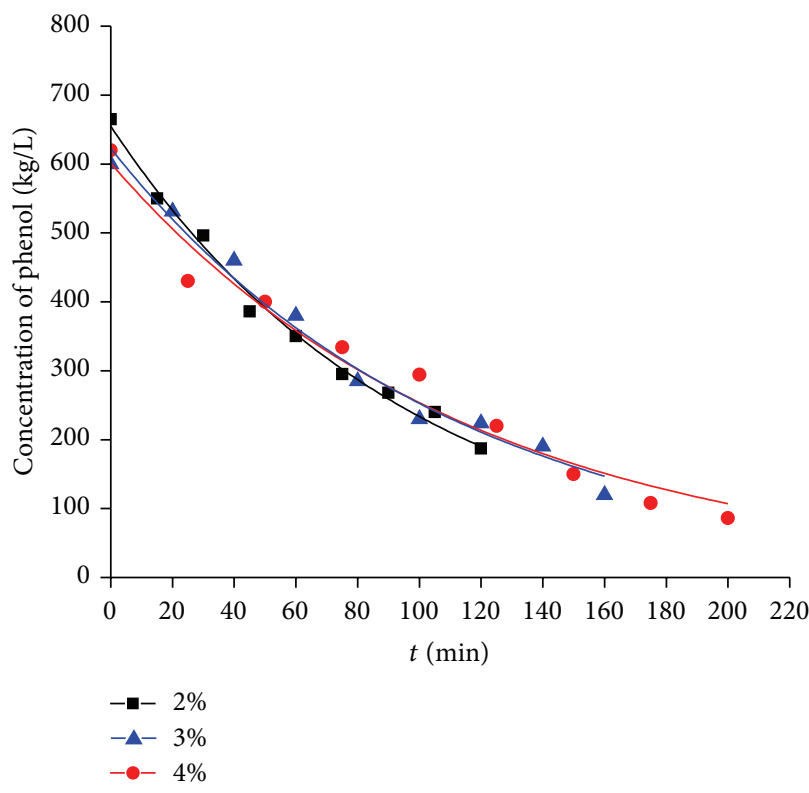

(a)

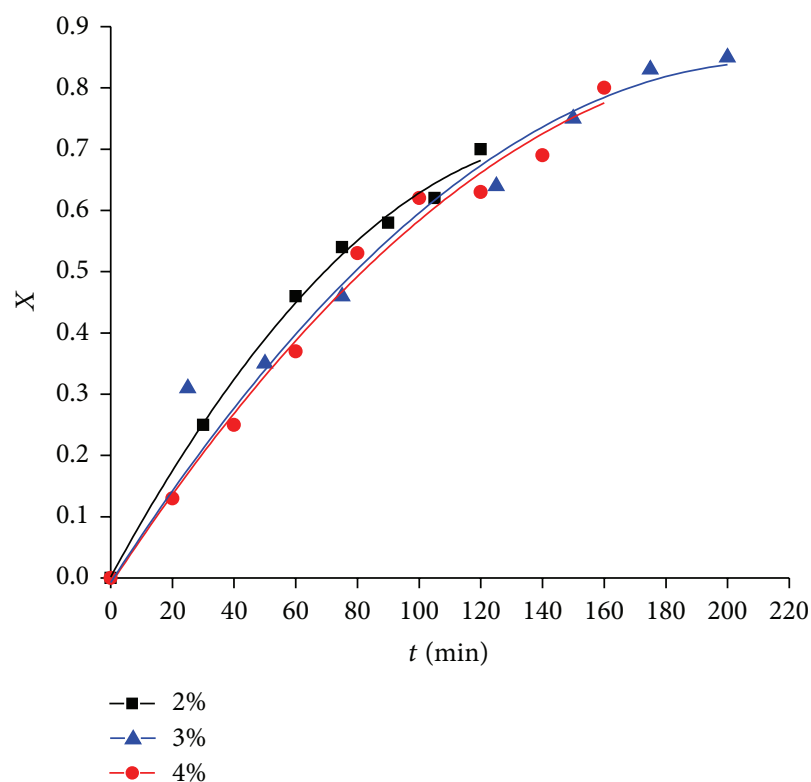

(b)

FIGURE 6: Variation of phenol concentration in different salinity wastewater over time. (a) Variation of remaining phenol concentration over time. (b) Removal rate of phenol over time.

TABLE 2: Theoretical value and measured data and orders of samples.

\begin{tabular}{|c|c|c|c|c|c|c|c|c|c|c|c|c|c|c|c|}
\hline \multicolumn{16}{|c|}{$\mathrm{C}_{6} \mathrm{H}_{6} \mathrm{O}(\mathrm{mg} / \mathrm{L})$} \\
\hline \multicolumn{8}{|c|}{$\mathrm{COD}(\mathrm{mg} / \mathrm{L})$} & \multicolumn{8}{|c|}{$E_{\mathrm{sp}}(\mathrm{kwh} / \mathrm{kgCOD})$} \\
\hline \multicolumn{2}{|c|}{400} & \multicolumn{2}{|c|}{600} & \multicolumn{2}{|c|}{800} & \multicolumn{2}{|c|}{1000} & \multicolumn{2}{|c|}{400} & \multicolumn{2}{|c|}{600} & \multicolumn{2}{|c|}{800} & \multicolumn{2}{|c|}{1000} \\
\hline Data & Rank & Data & Rank & Data & Rank & Data & Rank & Data & Rank & Data & Rank & Data & Rank & Data & Rank \\
\hline 47 & 1 & 87 & 1 & 237 & 1 & 287 & 1 & 7.23 & 1 & 6.22 & 1 & 12.3 & 1.5 & 13.0 & 3.5 \\
\hline 80 & 2 & 196 & 2 & 319 & 2 & 410 & 2 & 8.54 & 2 & 9.91 & 2 & 12.3 & 1.5 & 13.0 & 3.5 \\
\hline 112 & 3 & 306 & 3 & 456 & 3 & 636 & 3 & 9.38 & 3.5 & 10.5 & 3 & 13.0 & 4.5 & 13.0 & 3.5 \\
\hline 177 & 4 & 327 & 4 & 647 & 4 & 895 & 4 & 9.38 & 3.5 & 10.6 & 4.5 & 13.0 & 4.5 & 13.0 & 3.5 \\
\hline 274 & 5 & 442 & 5 & 866 & 5 & 1080 & 5 & 9.62 & 5 & 10.6 & 4.5 & 13.4 & 4.5 & 13.4 & 3.5 \\
\hline 403 & 6 & 496 & 6 & 1052 & 6 & 1154 & 6 & 10.5 & 6.5 & 10.8 & 6.5 & 13.4 & 4.5 & 13.4 & 3.5 \\
\hline 456 & 7 & 579 & 7 & 1106 & 7 & 1198 & 7 & 10.5 & 6.5 & 10.8 & 6.5 & 14.9 & 7.5 & 14.3 & 7 \\
\hline 513 & 8 & 602 & 8 & 1112 & 8 & 1378 & 8 & 11.6 & 9 & 11.1 & 8 & 14.9 & 7.5 & 14.9 & 8.5 \\
\hline 561 & 9 & 730 & 9 & 1138 & 9 & 1445 & 9 & 11.6 & 9 & 12.4 & 9.5 & 16.4 & 9 & 14.9 & 8.5 \\
\hline 561 & 10 & 743 & 10 & 1228 & 10 & 1486 & 10 & 12.4 & 10.5 & 12.4 & 9.5 & 17.4 & 10 & 16.8 & 10 \\
\hline 565 & 11 & 800 & 11 & 1359 & 11 & 1640 & 11 & 12.4 & 10.5 & 13.3 & 11 & 18.4 & 11 & 19.2 & 11 \\
\hline 634 & 12 & 907 & 12 & 1368 & 12 & 1736 & 12 & 14.2 & 12 & 14.3 & 12 & 20.3 & 12 & 20 & 12 \\
\hline 680 & 13 & 966 & 13 & 1404 & 13 & 1790 & 13 & 17.5 & 13 & 17.5 & 13 & 22.0 & 13 & 21.9 & 13 \\
\hline 740 & 14 & 1072 & 14 & 1576 & 14 & 1946 & 14 & 22.6 & 14 & 19.3 & 14 & 25.6 & 14 & 22.6 & 14 \\
\hline 759 & 15 & 1126 & 15 & 1592 & 15 & 2059 & 15 & 27.7 & 15 & 20.7 & 15 & 28.7 & 15 & 23.9 & 15 \\
\hline 792 & 16 & 1140 & 16 & 1632 & 16 & 2110 & 16 & 37.9 & 16 & 38.9 & 16 & 34.1 & 16 & 25.7 & 16 \\
\hline 953 & 17 & 1312 & 17 & 1760 & 17 & 2254 & 17 & & & & & & & & \\
\hline 980 & 18 & 1400 & 18 & 1906 & 18 & 2383 & 18 & & & & & & & & \\
\hline
\end{tabular}

From Figure $7(\mathrm{~h})$, you can see that when raw water salinity is $2 \%$, per-COD removal power consumption is the lowest; the main reason is that addition of electrolyte can improve wastewater conductivity and improve the treatment effect, thereby reducing energy consumption. But when wastewater salinity is high, it will promote the ${ }^{\bullet} \mathrm{OH}$ generation at anode.
As can be seen in Figure 7, when N-Step electrochemical reactor treats different mass concentration of phenol wastewater, per-COD power consumption tends to gradually reduce, and therefore it is consistent with theoretical model; the more the series, the less the reaction need. Table 3 is the relation and related coefficient treating different electrolyte concentration 


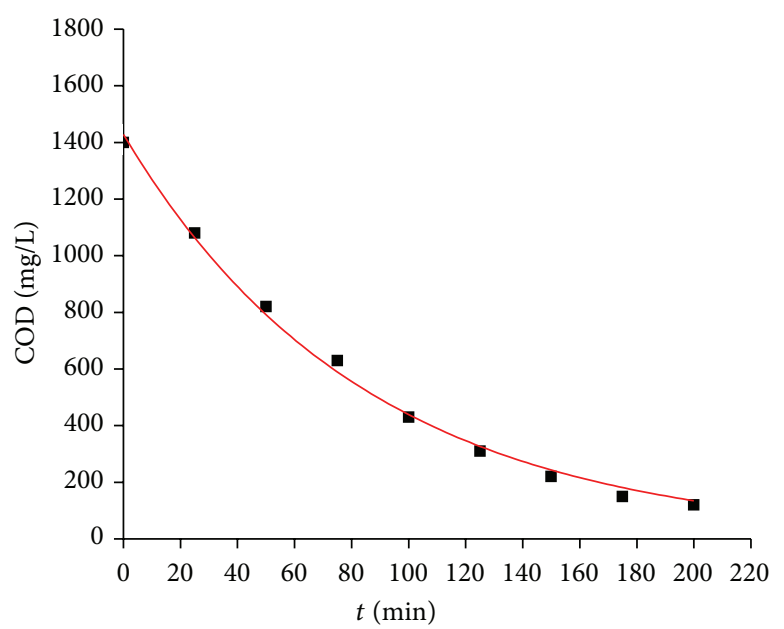

$-2 \%$

(a)

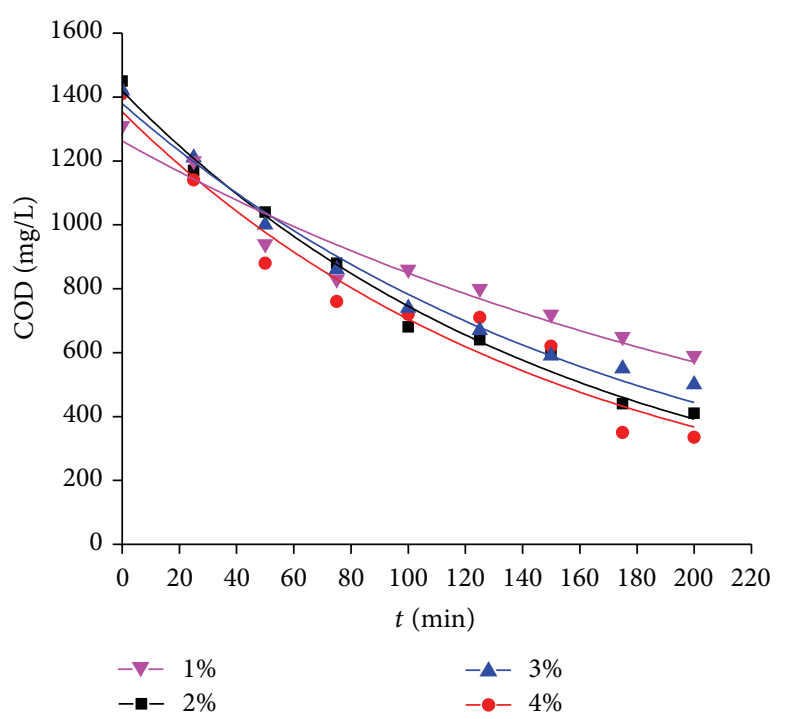

(c)

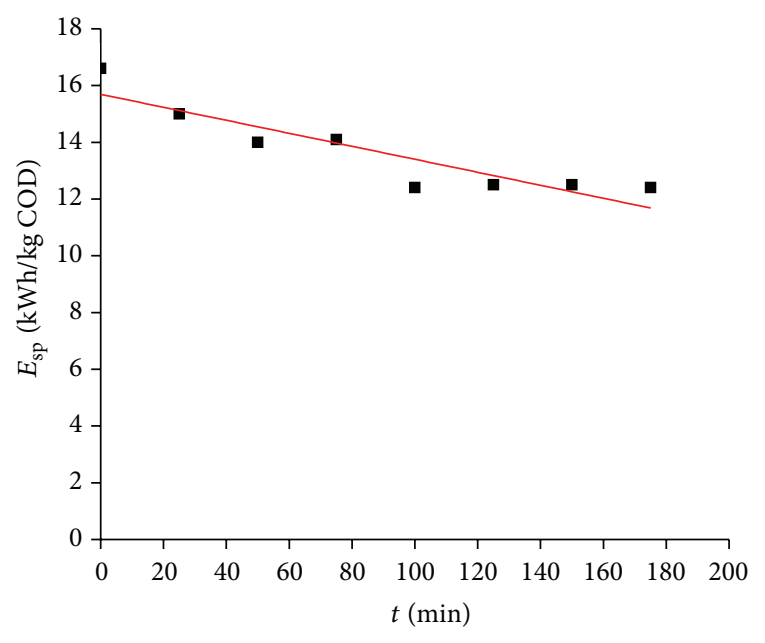

- $2 \%$

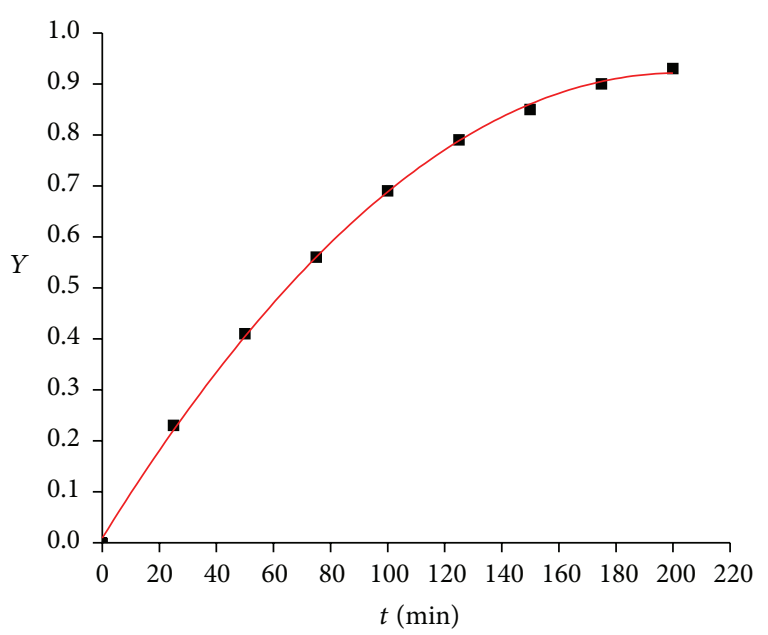

$-2 \%$

(b)

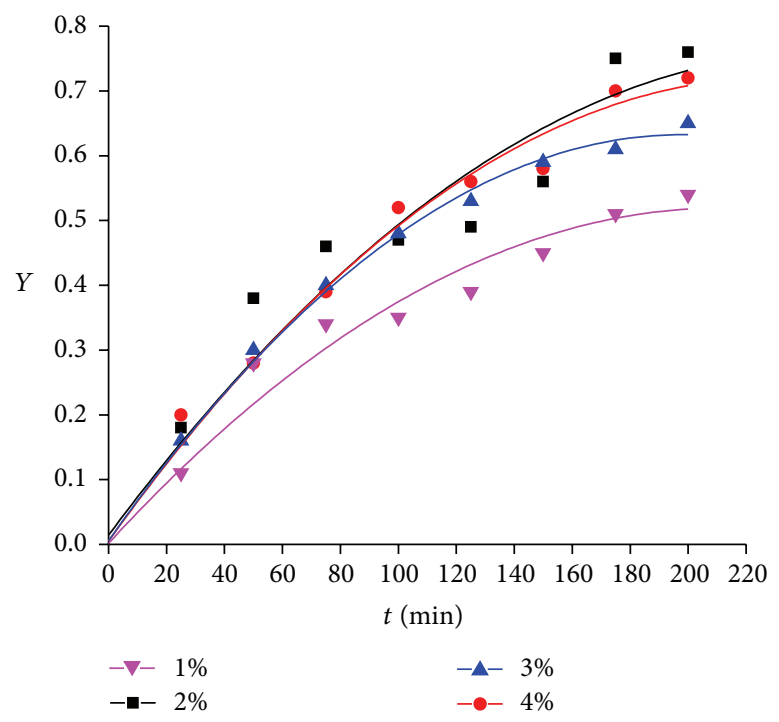

(d)

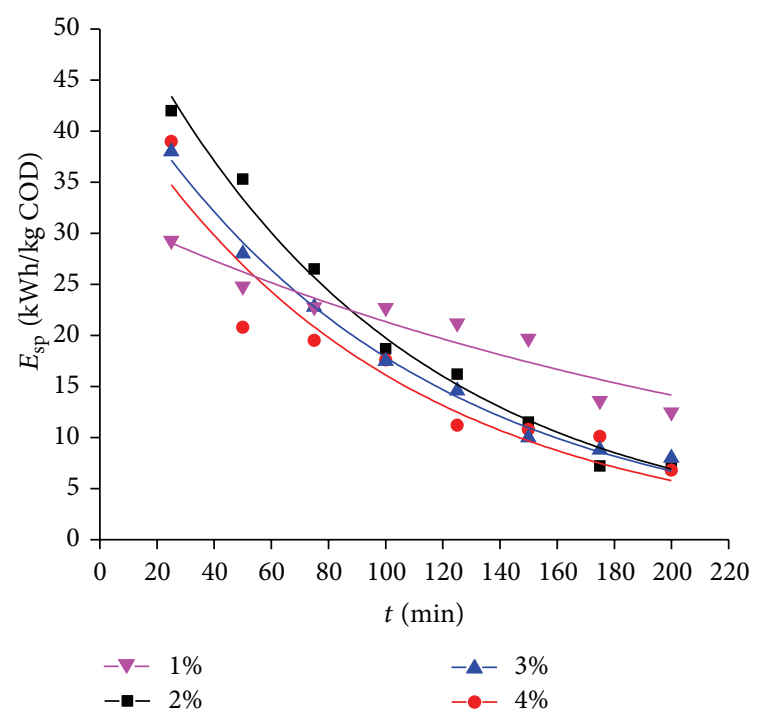

(f)

Figure 7: Continued. 


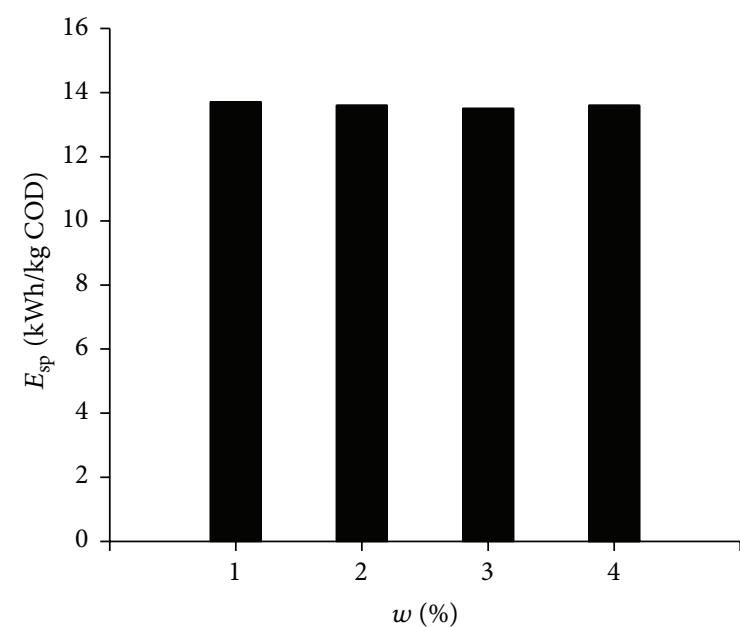

(g)

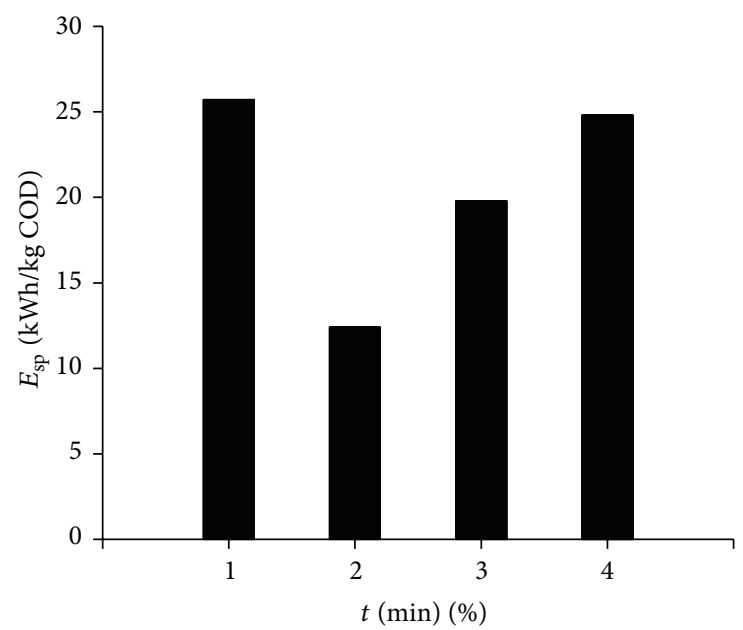

(h)

FIGURE 7: Variation of COD and power consumption in different salinity wastewater over time. (a) Variation of theoretical COD concentration over time. (b) Removal rate variation of theoretical COD in different electrolyte concentration phenol wastewater over time. (c) Measured COD in different electrolyte concentration phenol wastewater over time. (d) Removal rate variation of actual COD in different electrolyte concentration phenol wastewater over time. (e) Theoretical power consumption of different electrolyte concentration phenol wastewater treatment over time. (f) Actual power consumption of different electrolyte concentration phenol wastewater treatment over time. (g) Average theoretical power consumption in different electrolyte concentration phenol wastewater treatment. (h) Average actual power consumption in different electrolyte concentration phenol wastewater treatment.

TABLE 3: Relation and related coefficient treating different electrolyte concentration phenol wastewater.

\begin{tabular}{|c|c|c|}
\hline & COD & $E_{\mathrm{sp}}$ \\
\hline \multicolumn{3}{|l|}{$w(\%)$} \\
\hline \multicolumn{3}{|l|}{$1 \%$} \\
\hline \multicolumn{3}{|c|}{ Comparison expression } \\
\hline Theoretical value & $y=1535.9 e^{-0.013 x}$ & $y=15.924 e^{-0.002 x}$ \\
\hline Actual value & $y=1316.6 e^{-0.005 x}$ & $y=46.214 e^{-0.01 x}$ \\
\hline \multicolumn{3}{|l|}{$R^{2}$} \\
\hline Theoretical value & 0.9954 & 0.9028 \\
\hline Actual value & 0.9793 & 0.9901 \\
\hline \multicolumn{3}{|l|}{$2 \%$} \\
\hline \multicolumn{3}{|c|}{ Comparison expression } \\
\hline Theoretical value & $y=1535.9 e^{-0.013 x}$ & $y=15.924 e^{-0.002 x}$ \\
\hline Actual value & $y=1365.6 e^{-0.007 x}$ & $y=39.672 e^{-0.009 x}$ \\
\hline \multicolumn{3}{|c|}{ 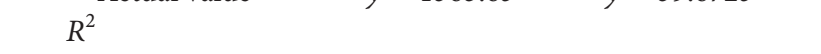 } \\
\hline Theoretical value & 0.9954 & 0.9028 \\
\hline Actual value & 0.9237 & 0.9332 \\
\hline \multicolumn{3}{|l|}{$3 \%$} \\
\hline \multicolumn{3}{|c|}{ Comparison expression } \\
\hline Theoretical value & $y=1535.9 e^{-0.013 x}$ & $y=15.924 e^{-0.002 x}$ \\
\hline Actual value & $y=1254.8 e^{-0.004 x}$ & $y=33.568 e^{-0.005 x}$ \\
\hline \multicolumn{3}{|c|}{ 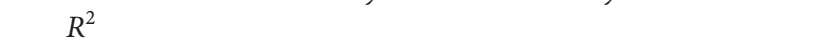 } \\
\hline Theoretical value & 0.9954 & 0.9028 \\
\hline Actual value & 0.9648 & 0.9748 \\
\hline \multicolumn{3}{|l|}{$4 \%$} \\
\hline \multicolumn{3}{|c|}{ Comparison expression } \\
\hline Theoretical value & $y=1535.9 e^{-0.013 x}$ & $y=15.924 e^{-0.002 x}$ \\
\hline Actual value & $y=1404.1 e^{-0.006 x}$ & $y=61.114 e^{-0.012 x}$ \\
\hline \multicolumn{3}{|c|}{ ק } \\
\hline Theoretical value & 0.9954 & 0.9028 \\
\hline Actual value & 0.9827 & 0.9831 \\
\hline
\end{tabular}

phenol wastewater. But the actual processing requires further inspection. It is uncertain whether the process is consistent with concentration prediction model.

Similarity degree between theoretical value and measured values is verified with rank tests. Inspection result is that there are no significance differences between theoretical and practical COD values.

Similarly, when the wastewater salinity is $2 \%, 3 \%$, and $4 \%$, its theoretical and practical power consumption were not significantly different; when the salinity is $1 \%$, its theoretical and practical power consumption have the distinctive difference. The reason is that, at the same operating current density treat wastewater, low salinity wastewater conductivity is poor; therefore, applied voltage is higher; at the same removal rate, power consumption is higher, causing the order of the actual power consumption to be fixed in a wide range, to influence the result of the rank tests. Therefore, from economy, electrochemical water treatment technology is not adaptable to low salinity wastewater.

\section{Conclusion}

$\mathrm{N}$-Step electrochemical reactor treats different mass concentration of phenol wastewater. The greater the concentration of organic matter is, the less the electricity needed is. If the concentration of organic matter is lower, the removal effect in the small current density is not ideal. N-Step electrochemical reactor treats different salinity of phenol wastewater. When salinity is $2 \%$, the organic matter removal effect is the best, and the power consumption is the lowest. When the electrolyte concentration is low, the wastewater conductivity is low, and mass transfer is slow. When the salinity is high, $\mathrm{SO}_{4}{ }^{2-}$ will be adsorbed on the surface of anode to influence 
the production of ${ }^{\bullet} \mathrm{OH}$, to reduce the removal of organic matter, and to increase the power consumption.

\section{Conflict of Interests}

The authors declare no conflict of interests regarding the publication of this paper.

\section{Acknowledgments}

This research is financially supported by the Scientific Research Foundation of Chongqing University of Arts and Sciences (R2014CH08), the Science and Technology Project from Chongqing (cstc2014jcyjA20023), the Natural Science Foundation of Yongchuan, Chongqing (Ycstc, 2014ac4001).

\section{References}

[1] A. M. Polcaro, S. Palmas, F. Renoldi, and M. Mascia, "Threedimensional electrodes for the electrochemical combustion of organic pollutants," Electrochimica Acta, vol. 46, no. 2-3, pp. 389-394, 2000.

[2] Y. Yavuz and A. S. Koparal, "Electrochemical oxidation of phenol in a parallel plate reactor using ruthenium mixed metal oxide electrode," Journal of Hazardous Materials, vol. 136, no. 2, pp. 296-302, 2006.

[3] O. Lefebvre and R. Moletta, "Treatment of organic pollution in industrial saline wastewater: a literature review," Water Research, vol. 40, no. 20, pp. 3671-3682, 2006.

[4] G. Chen, "Electrochemical technologies in wastewater treatment," Separation and Purification Technology, vol. 38, no. 1, pp. 11-41, 2004.

[5] C. Comninellis and A. Nerini, "Anodic oxidation of phenol in the presence of $\mathrm{NaCl}$ for wastewater treatment," Journal of Applied Electrochemistry, vol. 25, no. 1, pp. 23-28, 1995.

[6] X. Zhu, J. Ni, and P. Lai, "Advanced treatment of biologically pretreated coking wastewater by electrochemical oxidation using boron-doped diamond electrodes," Water Research, vol. 43, no. 17, pp. 4347-4355, 2009.

[7] C. Feng, N. Sugiura, S. Shimada, and T. Maekawa, "Development of a high performance electrochemical wastewater treatment system," Journal of Hazardous Materials, vol. 103, no. 1-2, pp. 65-78, 2003.

[8] S. Andreescu, D. Andreescu, and O. A. Sadik, "A new electrocatalytic mechanism for the oxidation of phenols at platinum electrodes," Electrochemistry Communications, vol. 5, no. 8, pp. 681-688, 2003.

[9] M. Panizza, A. Kapalka, and C. Comninellis, "Oxidation of organic pollutants on BDD anodes using modulated current electrolysis," Electrochimica Acta, vol. 53, no. 5, pp. 2289-2295, 2008.

[10] A. G. Vlyssides, M. Loizidou, P. K. Karlis, A. A. Zorpas, and D. Papaioannou, "Electrochemical oxidation of a textile dye wastewater using a Pt/Ti electrode," Journal of Hazardous Materials, vol. 70, no. 1-2, pp. 41-52, 1999.

[11] N. Mohan, N. Balasubramanian, and C. A. Basha, "Electrochemical oxidation of textile wastewater and its reuse," Journal of Hazardous Materials, vol. 147, no. 1-2, pp. 644-651, 2007.
[12] R. Pelegrini, P. Peralta-Zamora, A. R. De Andrade, J. Reyes, and N. Durán, "Electrochemically assisted photocatalytic degradation of reactive dyes," Applied Catalysis B: Environmental, vol. 22, no. 2, pp. 83-90, 1999.

[13] T.-C. An, X.-H. Zhu, and Y. Xiong, "Feasibility study of photoelectrochemical degradation of methylene blue with threedimensional electrode-photocatalytic reactor," Chemosphere, vol. 46, no. 6, pp. 897-903, 2002.

[14] J. P. Lorimer, J. Iniesta, M. Plattes et al., "Sonoelectrochemical effects in electro-organic systems," Ultrasonics Sonochemistry, vol. 7, no. 4, pp. 237-242, 2002.

[15] M. H. Zhou, Q. Z. Dai, L. C. Lei, C. Ma, and D. Wang, "Long life modified lead dioxide anode for organic wastewater treatment: electrochemical characteristics and degradation mechanism," Environmental Science and Technology, vol. 39, no. 1, pp. 363370, 2005.

[16] B. K. Körbahti and A. Tanyolaç, "Continuous electrochemical treatment of simulated industrial textile wastewater from industrial components in a tubular reactor," Journal of Hazardous Materials, vol. 170, no. 2-3, pp. 771-778, 2009.

[17] B. K. Körbahti and A. Tanyolaç, "Electrochemical treatment of simulated industrial paint wastewater in a continuous tubular reactor," Chemical Engineering Journal, vol. 148, no. 2-3, pp. 444-451, 2009.

[18] L. Szpyrkowicz and M. Radaelli, "Scale-up of an electrochemical reactor for treatment of industrial wastewater with an electrochemically generated redox mediator," Journal of Applied Electrochemistry, vol. 36, no. 10, pp. 1151-1156, 2006.

[19] L. Szpyrkowicz, "Application of electrochemical oxidation for treatment of industrial wastewater-the influence of reactor hydrodynamics on direct and mediated processes," Journal of Chemical Technology and Biotechnology, vol. 81, no. 8, pp. 1375$1383,2006$.

[20] K. Muthukumar, P. S. Sundaram, N. Anantharaman, and C. A. Basha, "Treatment of textile dye wastewater by using an electrochemical bipolar disc stack reactor," Journal of Chemical Technology and Biotechnology, vol. 79, no. 10, pp. 1135-1141, 2004.

[21] A. Sakalis, K. Mpoulmpasakos, U. Nickel, K. Fytianos, and A. Voulgaropoulos, "Evaluation of a novel electrochemical pilot plant process for azodyes removal from textile wastewater," Chemical Engineering Journal, vol. 111, no. 1, pp. 63-70, 2005. 

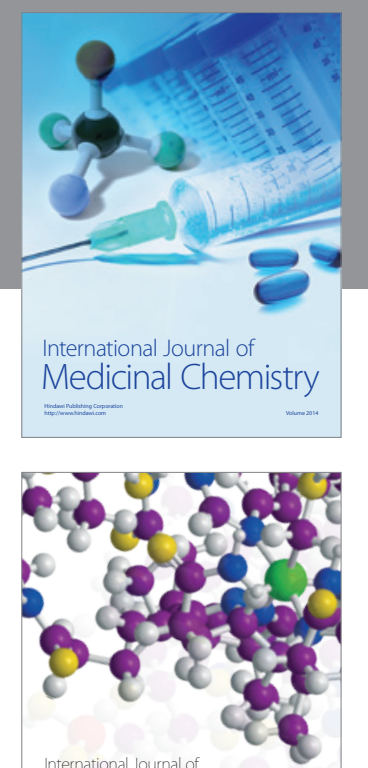

\section{Carbohydrate} Chemistry

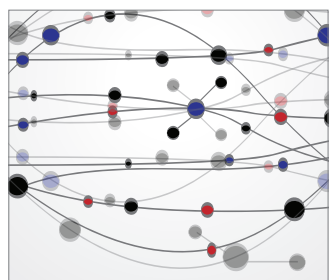

The Scientific World Journal
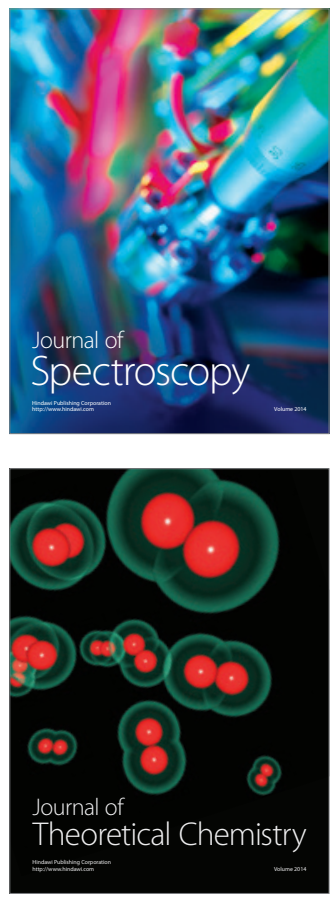
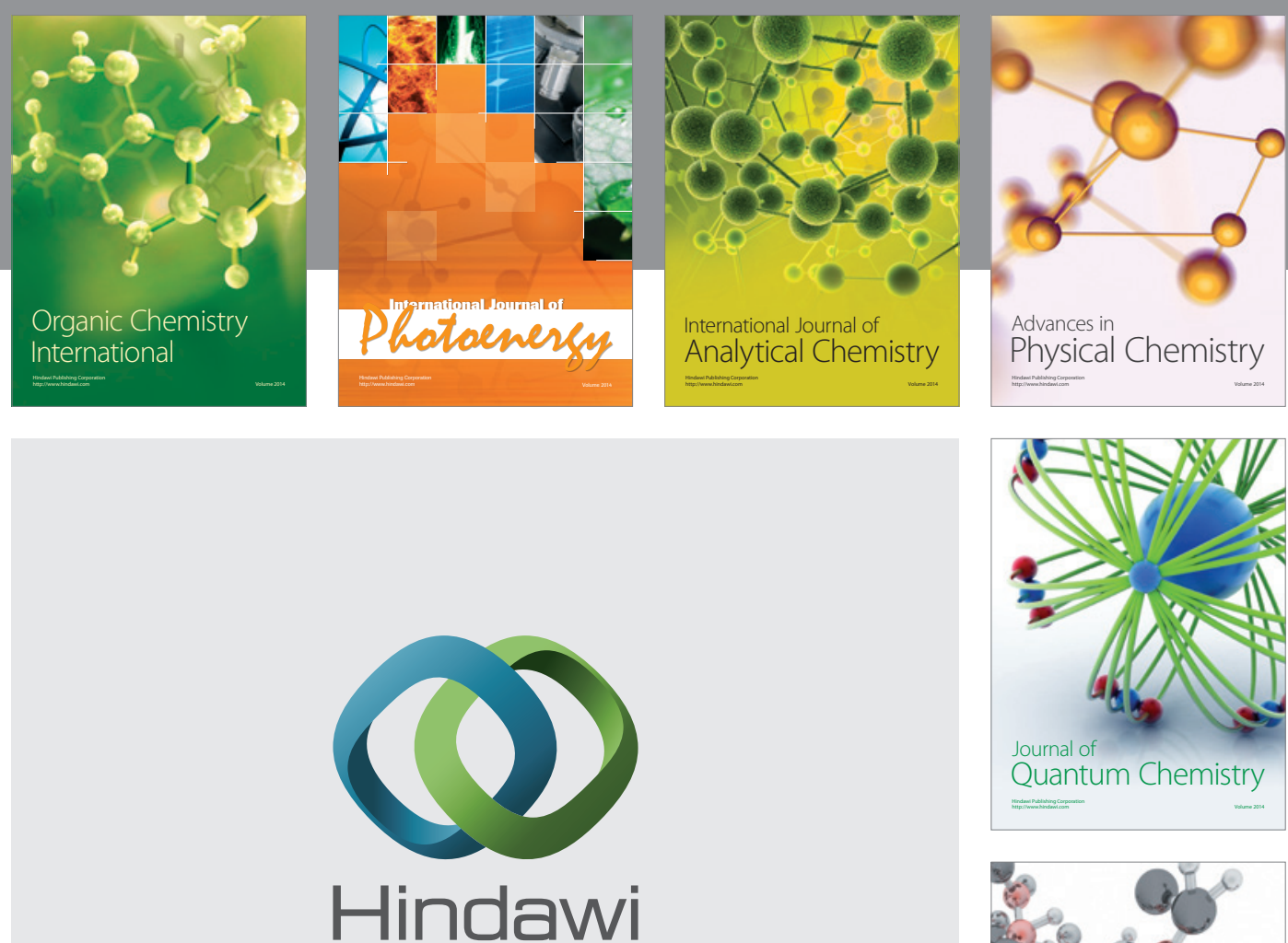

Submit your manuscripts at

http://www.hindawi.com

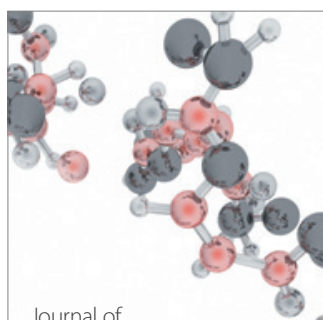

Analytical Methods

in Chemistry

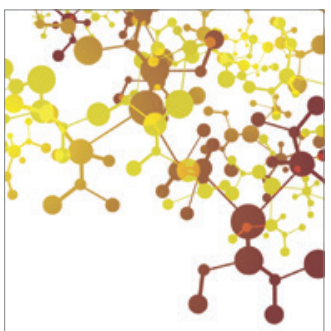

Journal of

Applied Chemistry

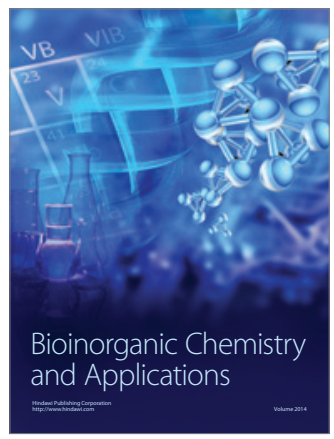

Inorganic Chemistry
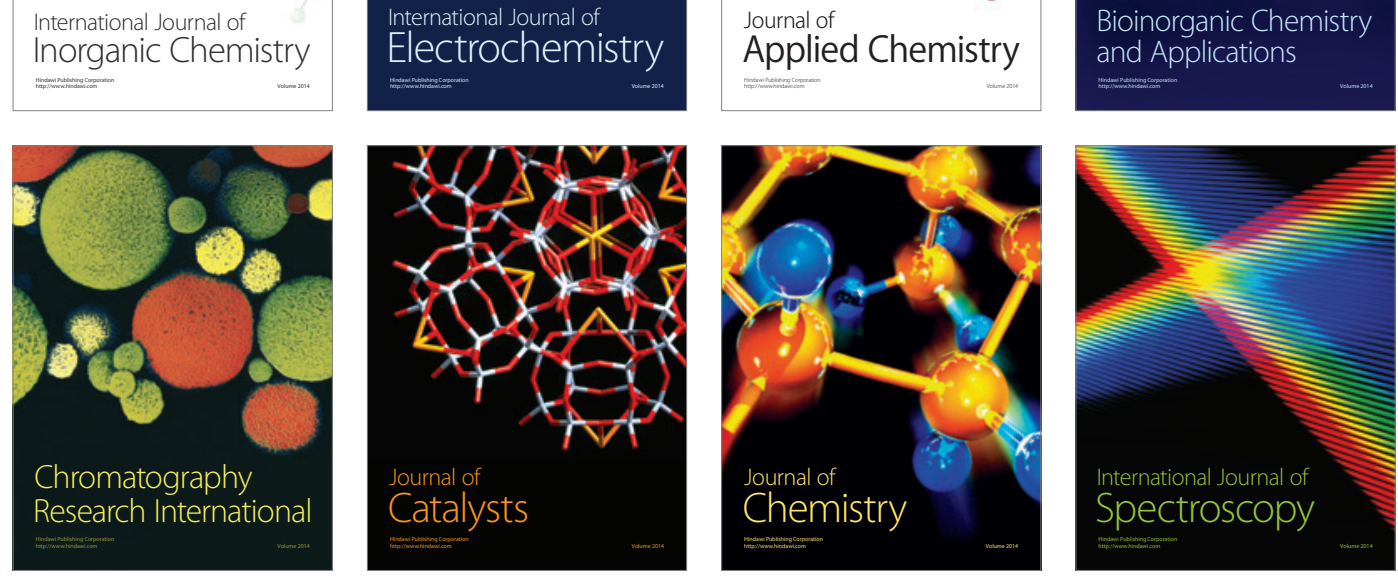